\title{
Long-term Treatment with Propranolol in Selected Cases of Fallot's Tetralogy
}

\author{
BENGT O. ERIKSSON, CLAES THORÉN, AND PER ZETTERQVIST \\ From the Division of Cardiology, Pediatric Clinics, Karolinska Institutet at Kronprinsessan Lovisas \\ Barnsjukhus, and Karolinska Sjukhuset, Stockholm, Sweden
}

Pharmacological blockade of beta-adrenergic receptors has found widespread use in recent years in several cardiovascular disorders where it is necessary to reduce the heart rate and myocardial contraction. The effect on myocardial contraction has been of primary importance in obstructive cardiomyopathy, as shown by Harrison et al. (1963). These authors showed that the blockade prevented the tendency of sympathomimetic agents to increase the obstruction caused by hypertrophic subaortic stenosis. The cyanotic spells occurring in some cases of Fallot's tetralogy have likewise been traced to spastic contraction of muscle bundles embracing the right ventricular outflow tract as a response to sympathetic stimulation (Johnson, 1961). The first report on the clinical effect of a beta-blocking agent, pronethalol, in Fallot's tetralogy indicated that a critical fall in arterial oxygen saturation could be reduced or even minimized (Honey, Chamberlain, and Howard, 1964). Singh and Gotsman (1966) confirmed the striking effect of the drug when given during cyanotic spells. The introduction of propranolol, a more potent beta-blocking agent that does not have the suggested carcinogenic effect of its predecessors, made it possible to try long-term administration in Fallot's anomaly as well.

The first reports on long-term treatment with propranolol in Fallot's tetralogy proved disappointing (Cumming and Carr, 1966; Ross, Robertson, and Watson, 1966). In selected cases, however, we have found that the effect is favourable.

In attempting to explain the apparent discrepancy, allowance must be made for the wide variation in primary anatomical features as well as the natural history of patients afflicted with Fallot's tetralogy. The function of this tetralogy depends on two main components, described in more detail by Becu et al. (1961) and Rudhe (1964). One of the components

Received May 8, 1968 is a ventricular septal defect with certain anatomical characteristics, situated immediately below the aortic root and "non-restrictive", i.e. of such a size that the pressures in both ventricles are equilibrated. The other component is a distortion of the right ventricular outflow tract caused by an abnormal topography of the parietal and septal bands adjacent to the hypertrophied crista supraventricularis. These two muscular bundles are both dislocated anteriorly, and along with the corpus portion of the crista they cause a more or less pronounced stenosis in the ostium infundibuli. The resulting obstruction to flow is more or less progressive. In extreme cases, a slight infundibular stenosis allowing a considerable left-to-right shunt may increase to such an extent in a few months that severe cyanosis results (Becu et al., 1961; Watson and Lowe, 1965).

Many cases, however, show additional abnormalities. Most common are further obstructive changes affecting the blood flow from the right ventricle to the pulmonary vessels, e.g. hypoplasia of this infundibulum or stenosis at the valvular level or in various parts of the pulmonary artery and its branches.

\section{SubJECTS AND METhodS}

During 1966 and 1967 a total of 65 children with Fallot's tetralogy, under 10 years of age, were seen in our clinics. Of these, 10 patients were selected for longterm treatment with propranolol, as they all showed evidence of an increase in the pulmonary blood flow after administration of the drug. In 4 cases $1-5 \mathrm{mg}$. propranolol was given intravenously, and in 6 cases 5-10 mg. was given perorally. The effect was studied phonocardiographically and by determining the arterial oxygen saturation before and after administration of the drug. By irritating the children until they cried, it was possible to study the effects of emotional stress on the auscultatory findings before and after propranolol administration. 
The basic clinical data for the 10 selected cases are given in the Table. Six of the patients had previously shown evidence of pure or predominant left-to-right shunt, and in only one of them (Case 9) had cyanosis been seen during the first month of life. Case 2 has already been described by Rudhe and Zetterqvist (1966) as a typical example of shunt reversal in Fallot. In all cases there was conclusive evidence of infundibular outflow tract obstruction, with functional variations from time to time. The pulmonary valve was moderately stenotic in Case 9 and slightly in Cases 4 and 8 . In Case 10 no selective angiocardiography was done, however. Cases 1, 4, and 10 had a history of rapid development of cyanosis and severe hypoxic attacks between 11 months and 2 years of age. Extreme functional variations were noticed in Case 4 and recorded as regards strength and duration of the systolic murmur along the left sternal border. During a state of anxiety the murmur was grade 1 but of high frequency and very short, whereas during sleep it was holosystolic and grade 5 .

For long-term treatment, propranolol was given perorally in a dosage of about $1 \mathrm{mg}$. $/ \mathrm{kg}$. body weight 3-4 times daily at 4-hour intervals. The effects were studied by regular clinical supervision. The variations in auscultatory findings were studied and documented with the aid of calibrated phonocardiography over the pulmonary area.

In 3 children (Cases 2, 3, and 6) the effects of peroral propranolol were studied during exercise. The work tests were performed on an Elema bicycle ergometer, the work load being increased stepwise in 6-minute periods until maximal tolerance. Heart rate, respiratory rate, and blood pressure were determined during the test. The test was first done without any propranolol being given that day, and was then repeated with the same loads one hour after $10 \mathrm{mg}$. propranolol had been given orally. This test was done 10 months after the institution of long-term treatment with propranolol.

\section{RESULTS}

In all these 10 selected cases of Fallot's tetralogy with evidence of infundibular stenosis and functional variations in the width of the infundibular orifice, the systolic murmur over the pulmonary area during beta-receptor blockade underwent a change indicative of increased pulmonary blood flow (Fig. 1, 2, and 3). The drug also entirely cancelled the opposite effect elicited by emotional stress. Crying was accompanied by a significant decrease in the intensity of the systolic murmur, particularly in late systole (Fig. 3). These effects were completely prevented after propranolol. The same effect upon the murmur was noticed during sleep. A very weak-grade 1-but extremely highfrequent early and short systolic murmur could in that way increase to grade 5 and change to a harsh holosystolic one.

The increase of arterial saturation was tested after intravenous blockade in some cases. In Case 1 the saturation increased from 70 to 78 per cent and the murmur increased at the same time from 2 to 4-5. In Case 7 the oxygen saturation rose from 40 to 76 per cent. The murmur became strong and the intensity maximum occurred later in systole (Fig. 2).

During long-term treatment none of the children had any attacks of cyanosis, not even in Case 10, where squatting had occurred daily before treatment. All the patients improved clinically and became more active physically, with better exercise tolerance, and were able to play more like normal children. They were also more relaxed and happy, with a better emotional tolerance.

TABLE

CLINICAL DATA IN 10 CHILDREN WITH FALLOT'S TETRALOGY SELECTED FOR LONG-TERM TREATMENT WITH PROPRANOLOL

\begin{tabular}{|c|c|c|c|c|c|c|c|c|c|c|}
\hline \multicolumn{3}{|c|}{$\begin{array}{l}\text { Case No., sex, } \\
\text { and age (yr.) }\end{array}$} & \multirow[t]{2}{*}{$\begin{array}{l}\text { Weight } \\
\text { (kg.) }\end{array}$} & \multirow{2}{*}{$\begin{array}{l}\text { Haemato- } \\
\text { crit } \\
(\%)\end{array}$} & \multirow{2}{*}{$\begin{array}{l}\text { Earlier } \\
\text { left-to- } \\
\text { right } \\
\text { shunt }\end{array}$} & \multirow{2}{*}{$\begin{array}{l}\text { Age at } \\
\text { onset of } \\
\text { cyanosis } \\
(y r .)\end{array}$} & \multicolumn{2}{|c|}{$\begin{array}{l}\text { Angiocardiographic } \\
\text { findings }\end{array}$} & \multirow{2}{*}{$\begin{array}{l}\text { Duration of } \\
\text { propranolol } \\
\text { treatment } \\
\quad \text { (mth.) }\end{array}$} & \multirow{2}{*}{ Comments } \\
\hline & & & & & & & $\begin{array}{c}\text { Valvular } \\
\text { pulmonary } \\
\text { stenosis }\end{array}$ & $\begin{array}{l}\text { Right- } \\
\text { sided } \\
\text { aorta }\end{array}$ & & \\
\hline 1 & $\mathbf{M}$ & 3 & $13 \cdot 3$ & 50 & + & $1 \frac{1}{2}$ & - & + & 15 & Cyanotic spells from $2 \mathrm{yr}$; \\
\hline 2 & $\mathbf{M}$ & 8 & $17 \cdot 1$ & 46 & + & - & - & - & 11 & Cyanosis during exercise; cor- \\
\hline 3 & $\mathbf{F}$ & $9 \frac{1}{2}$ & $25 \cdot 3$ & 53 & - & $5 / 12$ & - & + & 11 & $\begin{array}{l}\text { rective surgery at } 9 \text { yr. } \\
\text { lock anastomosis at } 6 \text { yr.; } \\
\text { corrective surgery at } 10 \frac{1}{2} \text { yr. }\end{array}$ \\
\hline $\begin{array}{l}4 \\
5\end{array}$ & $\begin{array}{l}\mathbf{M} \\
\mathbf{F}\end{array}$ & ${ }_{11}^{2 / 12}$ & $\begin{array}{l}10 \cdot 6 \\
28 \cdot 8\end{array}$ & $\begin{array}{l}50 \\
40\end{array}$ & $\begin{array}{l}+ \\
+\end{array}$ & $10^{1 \frac{1}{2}}$ & $\stackrel{(+)}{-}$ & \pm & $\begin{array}{l}11 \\
11\end{array}$ & $\begin{array}{l}\text { Down's syndrome; considerable } \\
\text { left-right shunt first } 3 \mathrm{yr} \text {; } \\
\text { attacks of cyanosis at } 10 \mathrm{yr} \text {. }\end{array}$ \\
\hline $\begin{array}{l}6 \\
7\end{array}$ & $\begin{array}{l}\mathbf{F} \\
\mathbf{F}\end{array}$ & $\begin{array}{l}5 \frac{1}{2} \\
6\end{array}$ & $\begin{array}{l}15 \cdot 9 \\
17 \cdot 5\end{array}$ & $\begin{array}{l}47 \\
51\end{array}$ & $(\overline{+})$ & $\begin{array}{l}7 / 12 \\
5 / 12\end{array}$ & $\overline{-}$ & \pm & $\begin{array}{l}9 \\
7 \frac{1}{2}\end{array}$ & $\begin{array}{l}\text { Mixed shunt at } 7 \mathrm{mth} \text {.; cyanotic } \\
\text { spells from } 2 \text { yr.; corrective }\end{array}$ \\
\hline $\begin{array}{l}8 \\
9\end{array}$ & $\underset{\mathbf{F}}{\mathbf{M}}$ & $\begin{array}{l}3 / 12 \\
3\end{array}$ & $\begin{array}{r}6 \cdot 1 \\
13 \cdot 5\end{array}$ & $\begin{array}{l}39 \\
70\end{array}$ & \pm & $\overline{1 / 12}$ & $\begin{array}{c}(+) \\
+\end{array}$ & $\overline{+}$ & $\begin{array}{l}5 \\
5\end{array}$ & $\begin{array}{l}\text { Cyanosis only by crying } \\
\text { Sister had operation for Fallot's } \\
\text { tetralogy; cyanosis at rest }\end{array}$ \\
\hline 10 & $\mathbf{M}$ & 3 & $11 \cdot 9$ & 40 & - & 2 & $?$ & + & 4 & Daily squatting from 2 yr. \\
\hline
\end{tabular}


There were no signs of decreased effect of the long-term treatment. When the drug was omitted for one day the condition, however, did become worse with reappearing symptoms.

The mean haematocrit before treatment was 49.4 per cent and remained at the same level during the period of treatment. In no case did the haematocrit increase.

No side-effects were noted during long-term treatment.

In Cases 2, 3, and 6, work tests were performed before and during blockade 10 months after the institution of long-term propranolol treatment. The changes during work in heart rate, respiratory rate, and systolic blood pressure are shown in Fig. 4. The decrease in heart rate was most pronounced at relatively high work loads. Thus, in Case 3 it was 21 per cent during maximal work and 9 per cent when the work load was moderate. In Case 2, in which a work load of only $100 \mathrm{kp} . \mathrm{m}$./min.' 'had represented a submaximal level, with a heart rate of 162 beats/min., the heart rate decreased by 31 per cent, whereas the decrease at $150 \mathrm{kp} . \mathrm{m} . / \mathrm{min}$. was less; however, the patient was now also able to work at a load of $200 \mathrm{kp} . \mathrm{m}$./min., with a heart rate of 154 . Case 3 had a heart rate of 160 and a very high respiratory rate, $54 / \mathrm{min}$. at maximal load, but after

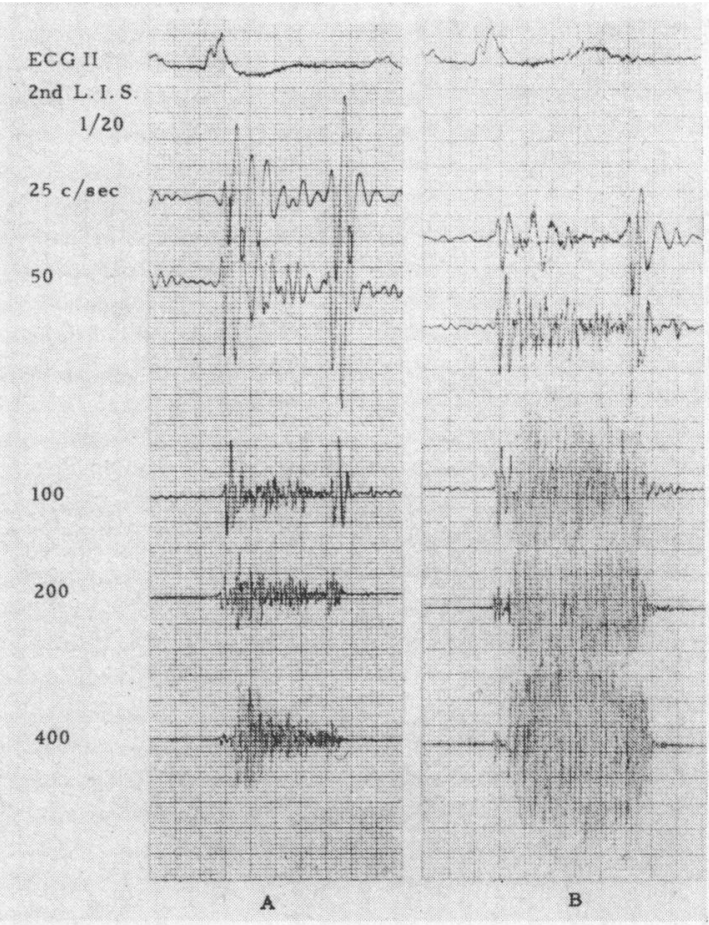

(a)
FIG. 1.-Effect of propranolol on the phonocardiogram, (a) in Case 1 and (b) in Case 2 at rest, before $(A)$ and after $(B)$ oral administration of propranolol. The increase in intensity of the systolic murmur during the beta-adrenergic blockade indicates increased pulmonary blood flow. Recorded over the 2 nd left interspace and with the same degree of amplification. The numerals denote the degree of amplification and medium frequencies in cycles/sec.

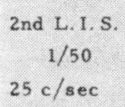

50

100

200

400

Ear-like 


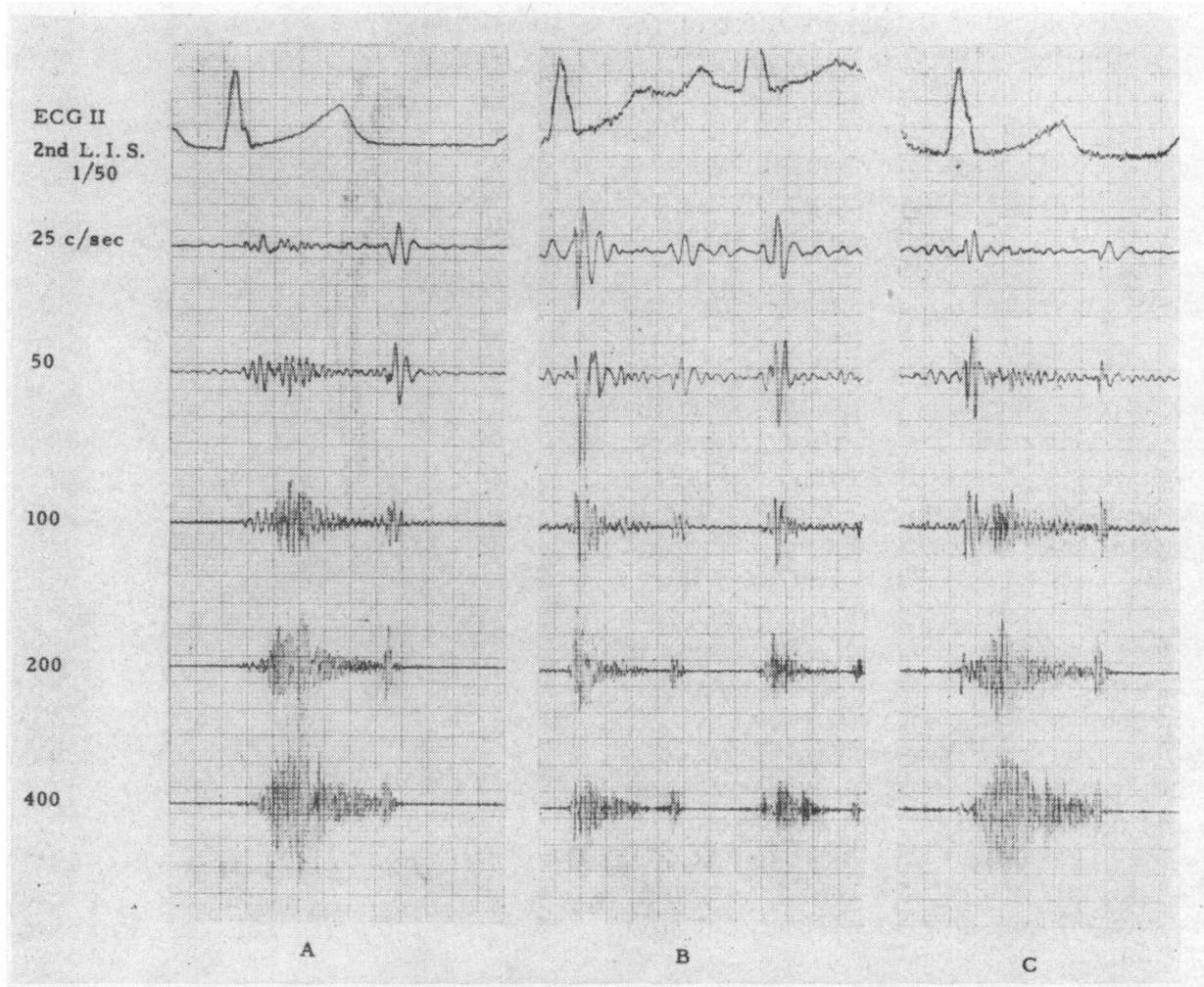

FIG. 2.-The functional variation of the stenotic murmur shown by phonocardiogram in Case 7 at rest (A), during crying (B) before and (C) after $1 \mathrm{mg}$. propranolol was given intravenously. The arterial oxygen saturation on these three occasions was 84,40 , and 65 per cent, respectively. Recordings from 2 nd left interspace. The numerals as in Fig. 1.

propranolol the heart rate decreased to 126 and the respiration to 41 at the same load.

The mean decrease in heart rate for the 3 cases was 2 beats/min. at rest, 19 in standing position, and 11 at rest 4 minutes after the test. During blockade the respiratory rate was lower on each load, as was the systolic blood pressure. The patients were all able to work longer and at somewhat higher work loads, indicating an improved exercise tolerance.

Three cases were given propranolol until they were successfully operated on with total corrective surgery. The resected infundibular portion did not show any fibrosis histologically.

\section{Discussion}

There seems to be no doubt that episodes of severe dyspnoea and cyanosis, with or without actual syncope, in infants and young children suffering from Fallot's tetralogy, are due to the obstruction of the right ventricular outflow tract being aggravated by sympathetic stimulation. Beta- receptor blocking agents may reduce the obstruction, resulting in an increase in pulmonary blood flow and a reduction of the right-to-left shunt, as demonstrated by Cumming and Carr (1967). Using indicator-dilution technique, these authors showed that the pulmonary flow might cease completely during an isoprenaline-induced cyanotic spell. The prerequisites for a beneficial effect of beta-receptor blockade are, first, that the obstruction to flow is localized mainly to the infundibulum and, second, that it is to some extent functional in nature, i.e. exaggerated by muscular contraction. No effect is to be expected when the obstruction is mainly due to valvular pulmonary stenosis, pulmonary artery hypoplasia, or multiple peripheral pulmonary stenosis. The same applies if the infundibular stenosis is narrow, being part of the primary malformation, or fixed because of secondary fibrosis.

Beta-adrenergic receptor activity is extensively involved in the cardiovascular response to emotional stress. This explains why the syncopal attacks in Fallot's tetralogy that occur mainly during infancy 
and early childhood are related to emotional reactions. In such situations the sudden pronounced beta-adrenergic stimulation leads to spastic contraction of the infundibular wall. A blockade of these effects was experienced by the children in our series and their parents as a dramatic improvement, fully comparable to the most favourable results of palliative surgery. The child and the parents are relieved from the anxiety of new attacks, and the considerable improvement in physical fitness enables the child to live a normal life. However, we wish to stress once again that this applies only to properly selected cases, and this is in agreement with the results reported by others (Honey et al., 1964; Cumming and Carr, 1967).

Selection of Cases for Therapy. Cases of Fallot's tetralogy, in which long-term propranolol treatment may conceivably be helpful, should be selected on the basis of history and anatomical features. Thus, obvious fluctuations in the degree of cyanosis at rest may reflect variations in infundibular tone and imply that the child is a candidate for beta-receptor blockade. Selective angiocardiography with right ventricular injection of the contrast medium is the method of choice in establishing the site of the main obstruction. This should apply even if the examination is performed during general anaesthesia, with partial or total release of any spastic contraction of the myocardium otherwise caused by emotional factors. The five patients in our series who did not become cyanotic until they were more than 1 year old represent the type of Fallot's tetralogy in which a pure or predominant left-to-right shunt slowly converts into a permanent right-to-left one (Rudhe and Zetterqvist, 1966). Thus, Case 5 was acyanotic up to the age of 10 years, and an 8-yearold boy (Case 2 ) became cyanotic only during exercise. In other cases the change ran a more rapid course (Becu et al., 1961; Ross et al., 1966). Such cases, acyanotic during early infancy, seem to be the most suitable ones for beta-receptor blockade.

A right-sided aortic arch, present in 6 of our 10 cases but almost never met with in ordinary ventricular septal defect, is of particular value for the early identification of Fallot's tetralogy, in spite of a pure predominant left-to-right shunt.

In our series the average haematocrit was as low as 49 per cent, which clearly shows that the average degree of cyanosis was moderate. This, however, by no means rules out the risk of serious episodes of cyanosis associated with emotional stress conditions.

We have not studied our entire material systematically enough to permit a statement about the proportion of cases suitable for propranolol treatment in an unselected series of Fallot's tetralogy.
It was not until early 1967 that our interest was really focused upon this new therapeutic principle, and some of our cases had undergone palliative or even corrective surgery before that time. Therefore, our proportion of 10 cases out of 65 , i.e. 15 per cent, obviously represents a minimum figure. According to the published reports there are, however, figures of 40-45 per cent of Fallot's tetralogy with a pure infundibular stenosis, which might be cases suitable for beta-receptor blockade.

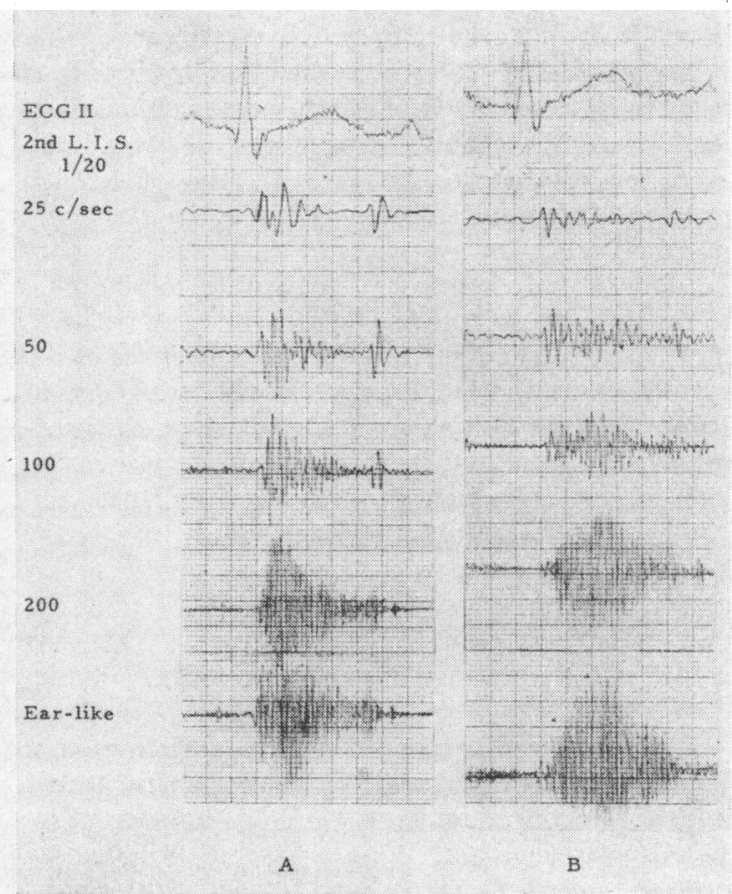

FIG. 3.-Phonocardiogram from the pulmonary area in Case 8, (A) before and (B) after propranolol. The stenotic murmur is increased with a prolonged intensity and a change from early systolic into holosystolic. The numerals as in Fig. 1.

Effect upon Systolic Murmur. It should not be necessary to resort to heart catheterization and artery puncture for the evaluation of the effect of the drug. It may well be sufficient to study the clinical condition, in particular the intensity and duration of the systolic murmur along the left sternal border. We found calibrated phonocardiography exceedingly valuable for documentation of the variations in the auscultatory findings. The difference in the strength and duration of the systolic murmur between full rest and a state of excitation may be extreme. During emotional stress an otherwise strong and harsh holosystolic murmur may become weak, or even inaudible, and early systolic, starting 
immediately after the first sound and lasting 5-10 hundredths of a second, or even less. At the same time it changes its frequency composition, becoming more exclusively high-frequent. Thus it mimics in several respects the type of murmur that characterizes a ventricular septal defect which is about to close spontaneously (Fig. 2).

After beta-receptor blockade, the systolic murmur persists more or less unchanged even during emotional stress (Fig. 2). Such an effect implies that propranolol treatment should be instituted. The effect upon the intensity of the murmur is the opposite of that seen in obstructive cardiomyopathy (Cherian et al., 1966) and in the cardiomyopathy of Friedreich's ataxia (C. Thorén, personal communication, 1967). The explanation of this discrepancy is that in the present type of Fallot's tetralogy the area of obstruction may be extremely narrow during late systole, and the ventricular septal defect conducts most of the stroke volume over to the left side so that no stenotic murmur is heard. This is very different from the characteristics of the systolic murmur in the conventional sense, e.g. in severe valvular pulmonary stenosis, where the murmur lasts longer and its intensity maximum comes later in systole the more pronounced the obstruction.

The information about variations in pulmonary blood flow obtained with the aid of phonocardiography renders artery puncture for the determination of oxygen saturation superfluous. This is a considerable advantage in paediatric cases.

Effect during Exercise. A patient suffering from Fallot's tetralogy may well be asymptomatic at rest but show a considerable limitation of exercise tolerance due to hypoxia. One characteristic effect of beta-adrenergic receptor blockade in healthy children is that the same work load can be performed at a significantly lower heart rate and with a tendency to improved peripheral oxygen utilization (Thorén, 1967). The duration of mechanical systole increases and the velocity of myocardial contraction decreases. In Fallot's anomaly these factors, together with the decrease in infundibular obstruction, effect an increase in the pulmonary blood flow, leading to a reduction in the degree of hypoxia. Honey et al. (1964) also showed that the decrease in arterial oxygen saturation during exercise was less pronounced during beta-receptor blockade in adults with Fallot's tetralogy, most of them having a functioning subclavian-pulmonary anastomosis. Shah and Kidd (1967), however, found only a slight to moderate improvement of the pulmonary blood flow during exercise in 4 out of 6 patients, not specified as to age and anatomical features. Our 3 patients, studied during exercise, all showed an ob- vious improvement in exercise tolerance during propranolol administration (Fig. 4). The wellknown fact that the effect of blockade is more obvious during emotional stress than during exercise (Eliasch, Rosén, and Scott, 1967) is apparently true even for cases of Fallot's tetralogy, and particularly so during early childhood.

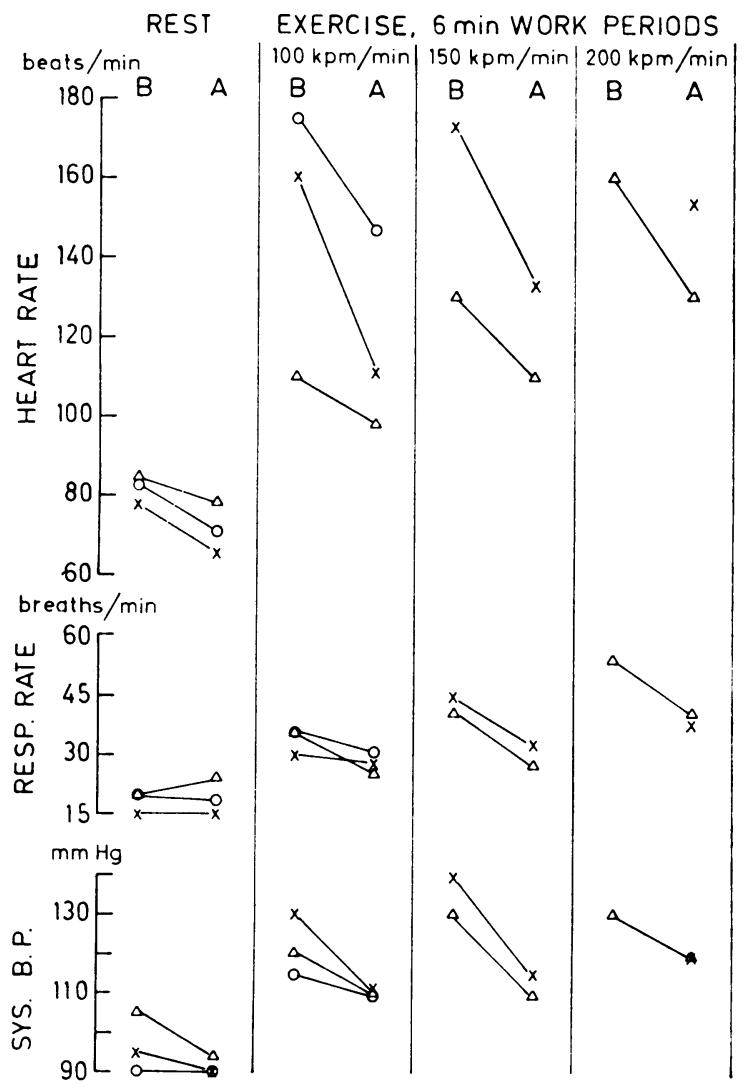

FIG. 4.-Changes in heart rate, respiratory rate, and systolic blood pressure produced by propranolol at rest and during work at different loads. There was a significant fall in heart rate and respiratory frequency during work. The systolic blood pressure also tended to decrease. B, before; $\mathrm{A}$, after. $\mathrm{X}=$ Case 2, $\Delta=$ Case $3, \mathrm{O}=$ Case 6 .

Long-term Treatment. Two main clinical effects are required of long-term treatment with betareceptor blockade in Fallot's tetralogy: (1) prevention of cyanotic spells, and (2) increase in mobility and play tolerance. Several authors have also called for further clinical observations on the longterm use of propranolol in this heart disease (Cumming and Carr, 1967; Ross et al., 1966; Shah and Kidd, 1967). Both the above effects were invariably achieved in our selected cases. In addition, the 
children increased their spontaneous activity and appeared to be strikingly relaxed and happy as compared to their previous mental state.

Cumming and Carr were disappointed with their long-term clinical results, despite the fact that their 3 infants, aged 2 to 8 months, were free from spells over a period of 1 to 3 months. Later, Cumming (1966) reported on a total of 6 unselected patients treated orally with propranolol for 1 to 8 months. He claimed that the failures of oral propranolol medication were due to severe organic narrowing of the right ventricular outflow tract. That the favourable effect in our cases should be ascribed to the oral long-term treatment was easily shown by omitting this for short periods: attacks of cyanosis reappeared, and the physical activity decreased. In none of our 10 cases did the effect of treatment tend to decline when the medication was continued for 4-15 months. Experiences similar to ours have been reported from the Children's Hospital in Birmingham (S. P. Singh, 1968, personal communication). The enthusiasm expressed by the parents of the treated children is also convincing. However, one should keep in mind that beta-receptor blockade is only a preventive measure directed towards the dangerous cyanotic spells, and a therapy that enables the child to lead a reasonably normal life while waiting until the proper time for total corrective surgery. If cyanosis at rest is severe and the haematocrit exceeds 60 per cent it may be necessary to carry out a systemic-to-pulmonary shunt or a pulmonafy valvotomy. Additional relief after palliative surgery can often be achieved by propranolol treatment (Honey et al., 1964; Cumming and Carr, 1967). One of our patients (Case 3) with a functioning subclavian-pulmonary anastomosis improved her exercise tolerance on propranolol treatment. If corrective surgery is not considered advisable because of additional handicaps that limit the child's activity, e.g. in Down's syndrome, this may strengthen the indication for even more prolonged propranolol treatment.

We are not yet able to predict whether long-term blockade may obviate the tendency for progressive hypertrophic and fibrotic changes to develop in the infundibular portion of the right ventricle. In our 3 operated cases there was no histological fibrosis. If this were so, it would also be of value from the surgical technical point of view.

Dose of Propranolol. Unsatisfactory results of long-term propranolol treatment may be due to inadequate dosage or too long intervals between the individual doses. Cumming and Carr (1967) reported the case of an infant of 6 months who was treated with a single daily dose of $15 \mathrm{mg}$. propranolol and was free from attacks of cyanosis except in the morning hours. Obviously the effect of treatment did not cover this period of the day. We have found it essential to administer the drug in such a way that the blockade effectively covers the part of the day when the child is awake. An early morning dose is recommended to be given to infants and small children as soon as they wake up. Because the effect of the drug drops significantly about four hours after peroral administration (Shanks, 1965), as a rule we have tried to administer the doses at 4-hour intervals. For many infants 3 daily doses are sufficient. It seems advisable to give the last dose before the afternoon meal, so that the blockade persists throughout the evening when the baby is expected to fall asleep. The individual dose varied between 5 and $20 \mathrm{mg}$., roughly corresponding to 1 $\mathrm{mg}$./kg. body weight. In several cases we somewhat exceeded the latter norm to avoid splitting the $10 \mathrm{mg}$. tablets into smaller portions than $5 \mathrm{mg}$. There seems to be no real disadvantage in moderate overdosage. There is evidently no change in the ratio between inotropic and chronotropic effects when the dosage is increased within reasonable limits (Shanks, 1965).

\section{SUMMARY}

Long-term peroral treatment with propranolol was instituted in 10 children aged 3 months to 11 years who suffered from Fallot's anomaly. The patients were selected on the basis of therapeutic tests that indicated a less pronounced infundibular obstruction during beta-receptor blockade. The effect was documented with the aid of phonocardiography, in which an increase in the intensity and duration of the systolic murmur over the pulmonary region reflected a corresponding increase in pulmonary blood flow.

The present series constitutes a selected and homogeneous group of patients with respect to anatomical and functional features of the heart anomaly. All had a late onset of cyanosis, and 6 of them had a previous history of predominant left-toright shunt. In most of them, significant variations in the intensity and other characteristics of the systolic murmur were obviously related to emotional stress on the one hand and complete relaxationsleep or general anaesthesia-on the other.

Exercise studies in 3 of the cases showed an increased tolerance to work after oral administration of propranolol.

Long-term treatment was instituted with about 1 mg./kg. body weight every 4 hours during the daytime. The average time of observation was 9 months. No cyanotic spells or hypoxic attacks 
appeared during treatment. In addition, the children became strikingly relaxed and more active in their play. There were no signs of a declining response to the drug during the period of treatment. In one case the observation time was 15 months. Long-term beta-adrenergic receptor blockade may make it possible to postpone palliative surgery until a more suitable age or even render it superfluous by enabling the child to reach the age at which correction of the anomaly can be undertaken. Therefore, the medication should no longer be considered merely an emergency treatment.

The clinical improvement documented in this series fully warrants the use of propranolol for longterm treatment in selected cases of Fallot's anomaly.

\section{REFERENCES}

Becu, L., Ikkos, D., Ljungqvist, A., and Rudhe, U. (1961). Evolution of ventricular septal defect and pulmonary stenosis with left to right shunt into classic tetralogy of Fallot. Amer. F. Cardiol., 7, 598.

Cherian, G., Brockington, I. F., Shah, P. M., Oakley, C. M., and Goodwin, J. F. (1966). Beta-adrenergic blockade in hypertrophic obstructive cardiomyopathy. Brit. med. F., 1, 895.

Cumming, G. R. (1966). Propranolol in Fallot's tetralogy. Lancet, 2, 1317.

—, and Carr, W. (1966). Relief of dyspnoeic attacks in Fallot's tetralogy with propranolol. Lancet, 1, 519.

- , and - (1967). Hemodynamic effects of propranolol in patients with Fallot's tetralogy. Amer. Heart f., 74, 29.
Eliasch, H., Rosén, A., and Scott, H. M. (1967). Systemic circulatory response to stress of simulated flight and to physical exercise before and after propranolol blockade. Brit. Heart F., 29, 671.

Harrison, D. C., Ross, J., Glick, G., Chidsey, C. A., and Braunwald, E. (1963). Hemodynamic effects of betaadrenergic blockade in hypertrophic subaortic stenosis. Clin. Res., 11, 167.

Honey, M., Chamberlain, D. A., and Howard, J. (1964). The effect of beta-sympathetic blockade on arterial oxygen saturation in Fallot's tetralogy. Circulation, 30, 501 .

Johnson, A. M. (1961). Norepinephrine and cyanotic attacks in Fallot's tetralogy. Brit. Heart F., 23, 197.

Ross, E. M., Robertson, P. G. C., and Watson, H. (1966) Failure of oral propranolol to maintain relief from paroxysmal syncopal attacks in Fallot's tetralogy after its successful intravenous use. Lancet, 2, 945.

Rudhe, U. (1964). Angiocardiography in pulmonary stenosis. Radiol. Clin. N. Amer., 2, 395.

- and Zetterqvist, P. (1966). Radiology of Fallot's anomaly with left to right and bi-directional shunts. Ann. Radiol., 9, 147.

Shah, P. M., and Kidd, L. (1967). Circulatory effects of propranolol in children with Fallot's tetralogy. Amer. f. Cardiol., 19, 653.

Shanks, R. G. (1965). The effect of propranolol on the cardiovascular responses to catecholamines in anaesthetized dogs. F. Physiol. (Lond.), 180, $21 \mathrm{P}$.

Singh, S. P., and Gotsman, M. S. (1966). Pronethalol for cyanotic attacks. Brit. Heart $\mathcal{F}$., 28, 98.

Thorén, C. (1967). Effects of beta-adrenergic blockade on heart rate and blood lactate in children during maximal and submaximal exercise. Acta paediat. scand., 56, Suppl. 177, p. 123.

Watson, H., and Lowe, K. G. (1965). Functional adaptations of the right ventricular outflow tract in congenital heart disease. Brit. Heart f., 27, 408. 